Wesleyan University

From the SelectedWorks of Charles A. Sanislow, Ph.D.

January, 2009

New onsets of substance use disorders in borderline personality disorder over 7 years of follow-ups: Findings from the Collaborative Longitudinal Personality Disorders Study

Marc Walter

John G. Gunderson

Mary C. Zanarini

Charles A. Sanislow, Wesleyan University

Carlos M. Grilo, et al. 


\title{
New onsets of substance use disorders in borderline personality disorder over 7 years of follow-ups: findings from the Collaborative Longitudinal Personality Disorders Study
}

\author{
Marc Walter ${ }^{1,2}$, John G. Gunderson', Mary C. Zanarini', Charles A. Sanislow ${ }^{3}$, Carlos M. Grilo ${ }^{3}$, \\ Thomas H. McGlashan ${ }^{3}$, Leslie C. Morey ${ }^{4}$, Shirley Yen $^{5}$, Robert L. Stout ${ }^{6}$ \& Andrew E. Skodol ${ }^{7}$ \\ Harvard Medical School, McLean Hospital, Belmont, MA, USA,' University of Basel, Department of Psychiatry, Basel, Switzerland, ${ }^{2}$ Yale University School of \\ Medicine, Department of Psychiatry, New Haven, CT, USA, ${ }^{3}$ Texas A\&M University, Department of Psychology, TX, USA, ${ }^{4}$ Brown University, Department of \\ Psychiatry and Human Behavior, Providence, RI, USA, ${ }^{5}$ Decision Science Institute, Providence, RI, USA ${ }^{6}$ and Institute for Mental Health Research, Phoenix, AZ, USA ${ }^{7}$
}

\begin{abstract}
Aims The purpose of this study was to examine whether patients with borderline personality disorder (BPD) have a higher rate of new onsets of substance use disorders (SUD) than do patients with other personality disorders (OPD). Design This study uses data from the Collaborative Longitudinal Personality Disorder Study (CLPS), a prospective naturalistic study with reliable repeated measures over 7 years of follow-up. Setting Multiple clinical sites in four northeastern US cities. Participants A total of 175 patients with BPD and 396 patients with OPD (mean age 32.5 years) were assessed at baseline and at 6, 12, 24, 36, 48, 60, 72 and 84 months. Measurements The Structured Clinical Interview for DSM-IV Axis I Disorders and the Diagnostic Interview for DSM-IV Personality Disorders were used at baseline, the Follow-Along version of the DIPD-IV and the Longitudinal Interval Follow-up Evaluation at the follow-up evaluations. Kaplan-Meier analyses were calculated to generate the time to new onsets. Findings BPD patients showed a shorter time to new onsets of SUD. Thirteen per cent of BPD patients developed a new alcohol use disorder and $11 \%$ developed a new drug use disorder, compared to rates of $6 \%$ and $4 \%$, respectively, for OPD. Nonremitted BPD and remitted BPD patients did not differ significantly in rates of new onsets of SUD. Conclusions BPD patients have a high vulnerability for new onsets of SUDs even when their psychopathology improves. These findings indicate some shared etiological factors between BPD and SUD and underscore the clinical significance of treating SUD when it co-occurs in BPD patients.
\end{abstract}

Keywords Alcohol use disorder, borderline personality disorder, CLPS, drug use disorder, new onset, substance use disorder.

Correspondence to: Marc Walter, Department of Psychiatry, University of Basel, Wilhelm Klein-Strasse 27, CH-4025 Basel, Switzerland. E-mail: marc.walter@upkbs.ch

Submitted 29 February 2008; initial review completed 26 July 2008; final version accepted 29 September 2008

\section{INTRODUCTION}

While it is well known that the psychiatric comorbidity rates in borderline personality disorder (BPD) patients include elevated rates of mood disorders, anxiety disorders, eating disorders and post-traumatic stress disorder (PTSD), BPD has shown a particularly strong association with substance use disorders (SUD) [1-10]. Previous studies have shown that half or more patients with BPD have co-occurring alcohol use disorder (AUD) or drug use disorder (DUD) [11-14], and that co-occurrence of these SUDs is associated with a greater severity of suicidality in BPD patients [15].

The standard explanation as to why BPD has increased rates of SUDs is a shared genetically based disposition to poor impulse control [16-18]; i.e. that both are impulse spectrum disorders [19-21]. This association of BPD with high impulsivity would link it to antisocial personality disorder (ASPD), a disorder linked epidemiologically and genetically to SUD [22-28]. However, 
although the markedly increased prevalence of both SUD and ASPD in relatives of BPD subjects [29-32] supports a probable spectrum relationship between these disorders, the genetic evidence currently available for the link between BPD and SUD is limited [33].

Environmental issues that predispose patients with either BPD or SUD to relapse may be as important. BPD subjects show significantly higher responses to psychosocial stressors than healthy control subjects [34,35] and specifically to interpersonal stressors than do patients with other personality disorders [36]. In SUD patients, taking drugs is driven frequently by cravings from drugconditioned stimuli and stress $[37,38]$ which also play a critical role in relapse after prolonged abstinence [39,40]. Thus, the psychosocial stressors may add vulnerability to both BPD and SUD and make BPD patients more vulnerable to new onsets of SUD.

The study reported here will examine whether the hypothesized spectrum relationship between BPD and SUD is demonstrated using longitudinal data. Currently, no previous studies have examined the vulnerability to new onsets of SUDs in BPD patients. This report takes place within a new context, in so far as longitudinal studies have recently shown that most BPD patients remit $[41,42]$. However, based on the hypothesis that both disorders share etiological factors, BPD patients might still retain a risk for developing a SUD in the long-term course. This study uses prospectively collected data from the Collaborative Longitudinal Personality Disorder Study (CLPS) [42] to investigate the risk of development a SUD in BPD versus other personality disorders (OPD). We will also examine whether non-remitted BPD have higher rates of new onsets of SUD.

\section{METHODS}

\section{Participants}

Participants for this study were enrolled in CLPS, an ongoing National Institute of Mental Health-funded, multi-site, prospective naturalistic study. Detailed descriptions of aims, design, assessment methods and sample characteristics and major findings of the Collaborative Longitudinal Personality Disorders Study (CLPS) project have been reported separately $[42,43]$. Briefly, the CLPS included treatment-seeking patients aged 18-45 years with one of four study personality disorders [schizotypal personality disorder (STPD); BPD; avoidant personality disorder, (AVPD); obsessive-compulsive disorder (OCPD)] for whom follow-up data were collected over 7 years $(6$, $12,24,36,48,60,72$ and 84 months). The four personality disorders selected for the study represent those which are the most prototypic and prevalent within the three DSM personality clusters: i.e, STPD for cluster A,
BPD for cluster B, AVPD for cluster C [36]. OCPD was added because factor analytical studies had shown that it is distinctive from the three DSM clusters [44]. Each of the four personality disorders derive from different theoretical frameworks. By focusing upon these four personality disorders, only about $15 \%$ of treatment-seeking patients meeting the criteria for any Axis II disorder were excluded [43].

Exclusion criteria were schizophrenia, schizoaffective disorders, psychotic disorder due to medical conditions and current substance intoxication or withdrawal. The study is based on 571 personality disorder participants with follow-up data over 7 years. Of the participants, $65 \%$ were women and $35 \%$ were men. The mean age was 32.5 [standard deviation $(\mathrm{SD})=8.1$ ] years.

For the purpose of the study, patients were divided into the following two groups: those diagnosed with BPD $(n=175)$ and a comparison group of those diagnosed with STPD, AVPD and OCPD (other personality disorder, OPD) $(n=396)$. The BPD group consisted of $75 \%$ women and $25 \%$ men, the OPD group of $60 \%$ women and $40 \%$ men. The mean ages were $32.1(\mathrm{SD}=7.8)$ for the $\mathrm{BPD}$ group and $32.7(\mathrm{SD}=8.3)$ for the OPD group.

'New onset' was defined as a new diagnosis of alcohol or drug use disorder for 1 month or longer in the followup, with no current or life-time SUD at baseline. To investigate the influence of remission from BPD upon the occurrence of new onsets of SUD, we divided the BPD subgroup into stably remitted and non-remitted patients after 2 years of follow-up. 'Stable remission' from BPD was defined as less than two BPD criteria for a period of at least 12 months in the second year of follow-up.

\section{Procedures}

All participants provided signed or written informed consent, following a full explanation of the study. Clinically experienced interviewers trained to pay particular attention to distinguishing Axis I mental state conditions from Axis II personality trait phenomena interviewed subjects who screened positive for the four targeted personality disorders with the Structured Clinical Interview for DSM-IV Axis I Disorders (SCID-I/P) [45] and the Diagnostic Interview for DSM-IV Personality Disorders (DIPDIV) [46]. The participants were evaluated again at 6,12 , $24,36,48,60,72$ and 84 months, with a follow-along version of the DIPD (DIPD-FAV) that records monthly variations in BPD criteria [47], and the Longitudinal Interval Follow-up Evaluation (LIFE) [48] that records weekly variations in DSM-IV SUD criteria.

The DIPD-FAV [47] was used to determine criteriabased outcome. It provided a record of the presence of BPD crieria for each month of the follow-up period. The follow-along reliability showed that the correlations 
Table 1 Frequency and percentage of co-occurrence of current and lifetime substance use disorder (SUD) in patients with personality disorder at baseline.

\begin{tabular}{lccc}
\hline & \multicolumn{2}{c}{$B P D(n=175)$} & \multicolumn{2}{l}{ OPD $(n=396)$} & \\
\cline { 2 - 3 } SUD & $n(\%)$ & $n(\%)$ & $P$ \\
\hline Alcohol use disorder & $91(52.0)$ & $152(38.4)$ & $\chi^{2}=9.20, \mathrm{df}=1, P=0.002$ \\
Alcohol Abuse & $30(17.1)$ & $52(13.1)$ & $\chi^{2}=1.59, \mathrm{df}=1, \mathrm{n} . \mathrm{s}$. \\
- Current alcohol abuse & $6(3.4)$ & $7(1.8)$ & $\chi^{2}=1.51, \mathrm{df}=1, \mathrm{n} . \mathrm{s}$. \\
- Lifetime alcohol abuse & $24(13.7)$ & $45(11.4)$ & $\chi^{2}=0.63, \mathrm{df}=1, \mathrm{n} . \mathrm{s}$. \\
Alcohol Dependence & $61(34.9)$ & $100(25.3)$ & $\chi^{2}=5.53, \mathrm{df}=1, P=0.013$ \\
Drug use disorder & $96(54.9)$ & $121(30.6)$ & $\chi^{2}=30.42, \mathrm{df}=1, P<0.0001$ \\
Drug Abuse & $18(10.3)$ & $29(7.3)$ & $\chi^{2}=1.41, \mathrm{df}=1, \mathrm{n} . \mathrm{s}$. \\
- Current drug abuse & $4(2.3)$ & $6(1.5)$ & $\chi^{2}=0.42, \mathrm{df}=1, \mathrm{n} . \mathrm{s}$. \\
- Lifetime drug abuse & $14(8.0)$ & $23(5.8)$ & $\chi^{2}=0.96, \mathrm{df}=1, \mathrm{n} . \mathrm{s}$. \\
Drug Dependence & $78(44.6)$ & $92(23.2)$ & $\chi^{2}=26.43, \mathrm{df}=1, P<0.0001$ \\
\hline
\end{tabular}

BPD, borderline personality disorder; OPD, other personality disorder.

between new raters for the number of borderline criteria (mean range $0.71-0.92$ ) and the correlation of new raters with original raters (mean range 0.75-0.94) was similar. Reliability for retrospective reporting on the DIPD-FAV was found to be good, with kappa scores ranging from 0.68 to 0.78 [42].

The LIFE [48] is a semistructured interview rating system which assesses the longitudinal course of Axis I disorders. Good to excellent reliability has been demonstrated consistently for the LIFE [49].

\section{Analyses}

All statistical analyses were performed with SPSS version 15.0 for Windows. The Kaplan-Meier product-limit technique [50] was used to generate time to new onset curves. A probability of $P<0.05$ was defined as the level of significance.

\section{RESULTS}

\section{SUD at baseline}

Table 1 shows the frequency of current and life-time substance use disorders (SUD) for BPD and the other personality disorders (OPD) at baseline. The rate for alcohol use disorder and drug use disorder was $52.0 \%$ and $54.9 \%$, respectively, in the BPD group, and $38.4 \%$ and $30.6 \%$ in the OPD group. Whereas BPD patients had a significantly higher rate of both alcohol dependence and drug dependence than OPD patients, they were not more apt to have alcohol and drug abuse.

\section{New onsets of SUD}

The 84 patients with BPD and 244 patients with OPD without a current or life-time alcohol use disorder at

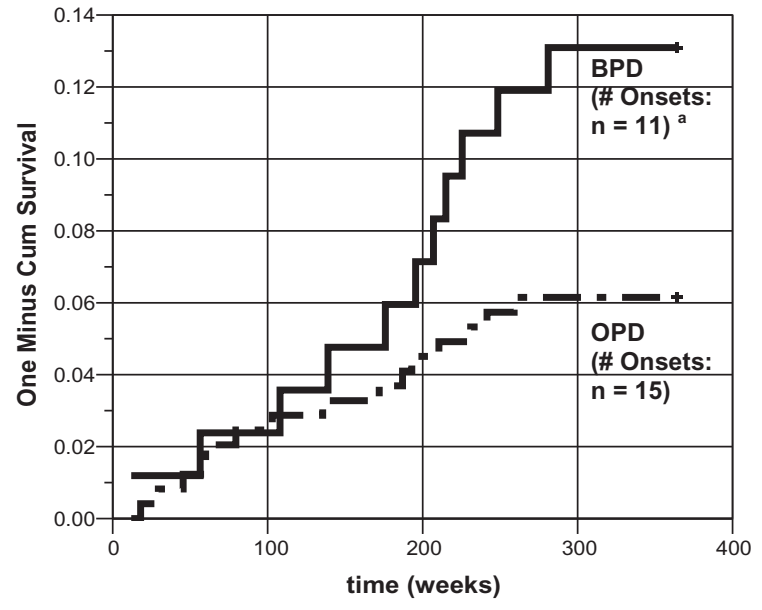

Figure I Time to new onsets of alcohol use disorder. BPD: borderline personality disorder $(n=84)$; OPD: other personality disorder $(n=244)$. aSignificant difference between test conditions (log-rank $\chi^{2}=4.04, \mathrm{df}=1, P=0.044$ )

baseline, and the $79 \mathrm{BPD}$ patients and 275 OPD patients without a current or life-time drug use disorder at baseline were investigated for new onsets of SUD during the 7 years of follow-up. New onsets of alcohol use disorder were $13 \%$ for BPD and $6 \%$ for OPD patients. Omnibus $\chi^{2}$ analysis revealed that the groups differed significantly in time to new onsets of alcohol abuse/dependence (logrank $\chi^{2}=4.04, \mathrm{df}=1, P=0.044$ ) (Fig. 1). As shown in Fig. 2, the groups (BPD, OPD) also differed significantly in their time to new onset of drug use disorder (log-rank $\left.\chi^{2}=7.64, \mathrm{df}=1, P=0.006\right): 11 \%(\mathrm{BPD})$ and $4 \%(\mathrm{OPD})$.

\section{New onsets of SUD in remitted versus non-remitted BPD}

After 2 years of follow-up, 85 BPD patients (48.6\%) showed a stable remission from their BPD diagnosis, 
whereas 90 BPD patients $(51.4 \%)$ did not. The cooccurring SUDs for the two groups at baseline are shown in Table 2. The remitted BPD patients had a significantly higher frequency of drug use disorder at baseline than the BPD patients who do not have remissions. The frequency of alcohol use disorder and any SUD at baseline in remitted and non-remitted BPD patients did not differ. As shown in Table 2, there were no significant differences in the new onset rates of SUD between remitted and nonremitted BPD groups.

\section{DISCUSSION}

This is the first study, to our knowledge, to examine the new onsets of alcohol use disorder (AUD) and drug use disorder (DUD) in patients with borderline personality disorder (BPD). Consistent with previous findings [5], we found that the prevalence rates of AUD and DUD in BPD at baseline was significantly higher than in OPD-a result that was biased by the absence of the other cluster

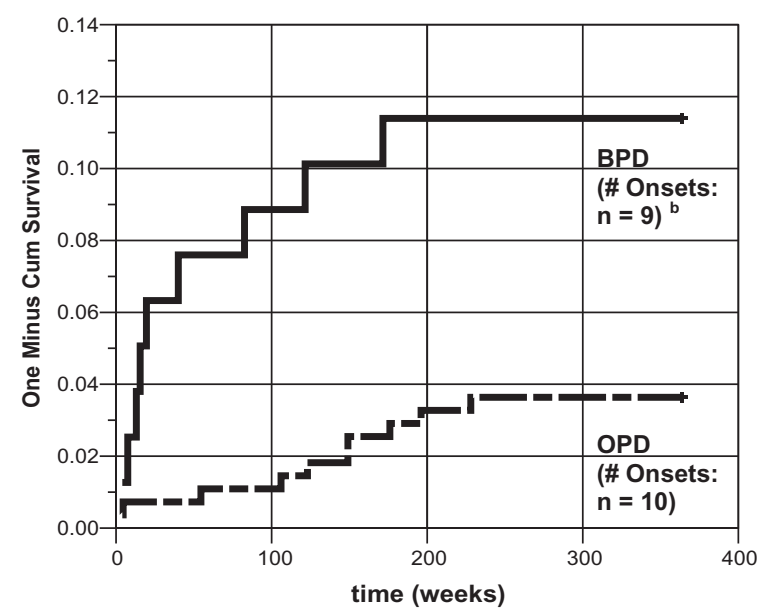

Figure 2 Time to new onsets of drug use disorder. BPD: borderline personality disorder $(n=79)$; OPD: other personality disorder $(n=275)$. 'bignificant difference between test conditions (log-rank $\left.\chi^{2}=7.64, d f=I, P=0.006\right)$
B disorder, ASPD, that has even higher rates of SUD $[51,52]$. This report notes, in addition, that the BPD patients showed a higher prevalence rate in alcohol and drug dependence than the OPD patients, but not in alcohol and drug abuse, suggesting that SUD in BPD patients is more severe than in OPDs. This conclusion is consistent with previous reports where severe substance use problems have been associated more with BPD and ASPD than with any other personality disorder [53-55].

The main finding is that the rate of new onsets of AUD is more than two times higher and of DUD is more than three times higher in BPD than in OPD. This confirms that BPD patients have particularly high vulnerability for the development of SUDs over the course of time. Our finding that new onsets of SUD do not differ significantly between remitted and non-remitted BPD patients adds to the impression of shared etiological factors between BPD and SUD. This conclusion is consistent with other studies which have shown that adolescents with a cluster B personality disorder have an increased risk of SUD in adulthood [56,57], and that a higher BPD criterion count is associated with early onset of SUD [58].

Although these findings suggest that SUDs share underlying pathologies with BPD (i.e. have a spectrum relationship), we could not rule out the possibility that other comorbid Axis I disorders-most notably, mood disorders - may have influenced the new onsets of SUD. However, the baseline comorbidity of major depressive disorder (MDD) and bipolar disorder were only moderately higher for BPD than for OPD [59,60]. Moreover, in other CLPS reports, we found that BPD patients fail to have higher rates of new onsets for MDD [61], and they have only slightly higher rates of new onsets of bipolar disorders than do CLPS patients with OPD [60]. It is also possible that these BPD patients with higher rates of new onsets of SUD are a BPD subgroup whose vulnerability reflects a higher level of impulsivity [62] than other BPD patients. Use of neurobiological measures for impulsivity that could shed light on whether that mechanism is present could add to future studies.

Table 2 Frequency and percentage of SUD in stably-remitted vs. non-remitted BPD.

\begin{tabular}{llll}
\hline & $\begin{array}{l}\text { Remitted BPD } \\
(n=85)\end{array}$ & $\begin{array}{l}\text { Non-remitted BPD } \\
(n=90)\end{array}$ & $P$ \\
\cline { 2 - 3 } SUD & $n(\%)$ & $n(\%)$ & $\chi^{2}=1.16, \mathrm{df}=1, \mathrm{n} . \mathrm{s}$. \\
$\begin{array}{l}\text { Baseline: } \\
\quad \begin{array}{l}\text { Alcohol use disorder } \\
\text { Drug use disorder }\end{array}\end{array}$ & $36(42.4)$ & $31(34.4)$ & $\chi^{2}=6.13, \mathrm{df}=1, P=0.013$ \\
$\begin{array}{l}\text { Follow-up: } \\
\text { New onsets of SUD }\end{array}$ & $48(56.5)$ & $36(40.0)$ & $\log$-rank $\chi^{2}=0.97, \mathrm{df}=1, \mathrm{n} . \mathrm{s}$.
\end{tabular}

BPD, borderline personality disorder; SUD, substance use disorder. 
Because our sample was restricted to four personality disorders, we could not examine rates of new onsets of SUDs in other personality disorders, particularly ASPD. Furthermore, our findings are limited by a lack of information as to which specific substances were used, no information of stressful life events during the follow-up period which could influence the onsets of SUD, and because of the limited sample sizes for assessing the role of remission in later years. Each of these limitations identify important questions that future studies will need to answer.

These limitations notwithstanding, we think our results retain some significant clinical implications. Continued substance dependence is a formidable resistance to treatment of BPD and is associated with a poor outcome [63-65]. Remission of SUD is sometimes followed by remission of BPD [66]. For these reasons, from a clinical point of view we believe that when substance abuse is comorbid with BPD it should become a priority in treatment planning [1]. Our finding that remitted BPD patients have a rate of new onsets of SUD as high as non-remitted patients points out the clinical importance of sustained attention to this risk. Clinicians should recognize that specific psychotherapeutic strategies have been developed to treat the inter-related symptoms of substance abuse and co-occurring personality disorders $[67,68]$ and specifically for treating BPD patients with comorbid substance abuse [69,70].

This is the first examination of new onsets of alcohol use disorder and drug use disorder in BPD patients in a prospective longitudinal design with adequate sample size. It establishes that BPD patients-even when remitted-seem to have a higher vulnerability than patients with other personality disorders - with the probable exception of ASPD—for the development of a SUD. This conclusion is consistent with both the concept of a spectrum relationship and with the clinical wisdom that substance abuse is a particularly hazardous form of comorbidity for patients with BPD.

\section{Declarations of interest}

None.

\section{Acknowledgement}

This work was funded by the National Institute of Mental Health (NIMH). Award sites include Brown University Department of Psychiatry and Human Behavior (MH50837), Columbia University College of Physicians and Surgeons and New York State Psychiatric Institute (MH50839), Harvard Medical School and McLean Hospital (MH50840), Texas A\&M University (MH50838), Yale University School of Medicine (MH50850) and MH073708 (Dr Sanislow). This manuscript has been reviewed and approved by the Publications Committee of the Collaborative Longitudinal Personality Disorders Study.

\section{References}

1. Gunderson J. G., Links P. S. Borderline Personality Disorder. A Clinical Guide, 2nd edn. Washington, DC: American Psychiatric Press; 2008.

2. Akiskal H. S., Chen S. E., Davis G. C., Puzantian V. R., Kashgarian M., Bolinger J. M. Borderline: an adjective in search for a noun. J Clin Psychiatry 1985; 46: 41-8.

3. Akiskal H. S. The temperament borders of affective disorders. Acta Psychiatr Scand 1994; 89: S32-37.

4. Oldham J. M., Skodol A. E., Kellman H. D., Hyler S. E., Doidge N., Rosnick L. et al. Comorbidity of axis I and axis II disorders. Am J Psychiatry 1995; 152: 571-8.

5. McGlashan T. H., Grilo C. M., Skodol A. E., Gunderson J. G., Shea M. T., Morey L. C. et al. The collaborative longitudinal personality disorder study: baseline axis I/II and II/II diagnosis co-occurrence. Acta Psychiatr Scand 2000; 102: 25664.

6. Dolan-Sewell R. T., Krueger R. F., Shea M. T. Co-occurrence with syndrome disorders. In: Livelsey W. J., editor. Handbook of Personality Disorders. New York: Guilford Press; 2001, p. $84-104$.

7. Shea M. T., Stout R. L., Yen S., Pagano M., Skodol A., Morey L. C. et al. Associations in the course of personality disorders and Axis I disorders over time. J Abnorm Psychol 2004; 113: 499-508.

8. Tyrer P., Gunderson J., Lyons M., Tohen M. Special feature: extent of comorbidity between mental state and personality disorders. J Pers Disord 1997; 11: 242-59.

9. Skodol A. E., Oldham J. M., Gallaher P. E. Axis II comorbidity of substance use disorders among patients referred for treatment of personality disorders. Am J Psychiatry 1999; 156: 733-8.

10. Trull T. J., Sher K. J., Minks-Brown C., Durbin J., Burr R. Borderline personality disorder and substance use disorders. Clin Psychol Rev 2000; 20: 235-53.

11. Grilo C. M., Martino S., Walker M. L., Becker D. F., Edell W. S., McGlashan T. H. Controlled study of psychiatric comorbidity in psychiatrically hospitalized young adults with substance use disorders. Am J Psychiatry 1997; 154: 3051307.

12. Zanarini M. C., Frankenburg F. R., Dubo E. D., Sickel A. E., Trikha A., Levin A. et al. Axis I comorbidity of borderline personality disorder. Am J Psychiatry 1998; 155: 1733-9.

13. Zanarini M. C., Frankenburg F. R., Hennen J., Reich D. B., Silk K. R. Axis I comorbidity in patients with borderline personality disorder: 6 year follow-up and prediction of time to remission. Am J Psychiatry 2004; 161: 2108-14.

14. Links P. S., Heslegrave R. J., Mitton J. E., Van Reekum R., Patrick J. Characteristics of borderline personality disorder: a Canadian study. Can J Psychiatry 1995; 33: 336-54.

15. Yen S., Shea M. T., Pagano M., Sanislow C. A., Grilo C. M., McGlashan T. H. et al. Axis I and axis II disorders as predictors of prospective suicide attemps: findings from the collaborative longitudinal personality disorders study. J Abnorm Psychol 2003; 112: 375-81.

16. Merikangas K. R., Stolar M., Stevens D. E., Goulet J., Preisig M. A., Fenton B. et al. Familial transmission of substance use disorders. Arch Gen Psychiatry 1998; 55: 973-9. 
17. Miles D. R., Stallings M. C., Young S. E., Hewitt J. K., Crowley T. J., Fulker D. W. A family history and direct interview study of familial aggregation of substance abuse. Drug Alcohol Depend 1998: 49: 105-14.

18. White C. N., Gunderson J. G., Zanarini M. C., Hudson J. I. Family studies of borderline personality disorder: a review. Harv Rev Psychiatry 2003; 11: 8-19.

19. Zanarini M. C. BPD as an impulsive spectrum disorder. In: Paris J., editor. Borderline Personality Disorder: Etiology and Treatment. Washington, DC: American Psychiatric Press; 1993, p. 67-85.

20. Links P. S., Heslegrave R., van Reekum R. Impulsivity: core aspect of borderline personality disorder. J Personal Disord 1999; 12: 1-9.

21. Siever L. J., Davis K. L. A psychobiological perspective on the personality disorder. Am J Psychiatry 1991; 148: 1647-58.

22. Pickens R. W., Svikis D. S., McGue M., LaBudaa M. C. Common genetic mechanism in alcohol, drug, and mental disorder comorbidity. Drug Alcohol Depend 1995; 39: 12938.

23. Grove W. M., Eckert E. D., Heston L., Bouchard T. J. Jr, Segal N., Lykken D. T. Heritability of substance abuse and antisocial behavior: a study of monozygotic twins reared apart. Biol Psychiatry 1990; 27: 1293-304.

24. Health A. C., Cloninger C. R., Martin N. G. Testing a model for the genetic structure of personality: a comparison of the personality systems of Cloninger and Eysenck. J Pers Soc Psychol 1994; 66: 762-75.

25. Howard M. O., Kivlahan D., Walker R. D. Cloninger's tridemensional theory of personality and psychopathology: applications to substance use disorder. J Stud Alcohol 1997; 58: 48-66.

26. Slutske W. S., Heath A. C., Dinwiddie S. H., Madden P. A., Buchholz K. K., Dunne M. P. et al. Common genetic risk factors for conduct disorder and alcohol dependence. J Abnorm Psychol 1998; 107: 363-74.

27. Krueger R. F. The structure of common mental disorder. Arch Gen Psychiatry 1999; 56: 921-6.

28. Johnson B. A., Brent D. A., Connolly J., Bridge J., Matta J., Constantine D. et al. Familial aggregation of adolescent personality disorders. J Am Acad Adol Psychiatry 1995; 34: 798-804.

29. Pope H. G. Jr, Jonas H. M., Hudson J. I., Cohen B. M., Gunderson J. G. The validity of DSM-III borderline personality disorder. A phenomenologic, family history, treatment response, and long-term follow-up study. Arch Gen Psychiatry 1983; 40: 23-30.

30. Loranger A. W., Tulis E. H. Family history of alcoholism in borderline personality disorder. Arch Gen Psychiatry 1985; 42: 153-7.

31. Silverman J. M., Pinkham L., Horvarth T. B., Coccaro E. F., Klar H., Schear S. et al. Affective and impulsive personality disorder traits in the relatives of patients with borderline personality disorder. Am J Psychiatry 1991; 148: 3781385.

32. Riso L. P., Klein D. N., Anderson R. L., Ouimette P. C. A family study of outpatients with borderline personality disorder and no history of mood disorder. J Pers Disord 2000; 14: 208-17.

33. Jang K. L., Vernon P. A., Livesley W. J. Personality disorder traits, family environment and alcohol misuse: a multivariate behavioural genetic analysis. Addiction 2000; 95: 87388.

34. Simeon D., Knutelska M., Smith L., Baker B. B., Hollander E.
A preliminary study of cortisol and norepinephrine reactivity to psychosocial stress in borderline personality disorder with high and low dissociation. Psychiatry Res 2007; 149: 177-84.

35. Walter M., Bureau J.-F., Holmes B., Bertha E. A., Hollander M., Wheelis J. et al. Cortisol response to interpersonal stress in young adults with borderline personality disorder: a pilot study. Eur Psychiatry 2008; 23: 201-4.

36. Pagano M. E., Skodol A. E., Stout R. L., Shea M. T., Yen S., Grilo C. M. et al. Stressful life events as predictors of functioning: findings from the Collaborative Longitudinal Personality Disorders Study. Acta Psychiatr Scand 2004; 110: 421-9.

37. Le Moal M., Koob G. F. Drug addiction: pathways to the disease and pathophysiological perspectives. Eur Neuropsychopharmacol 2007; 17: 377-93.

38. Walter M., Wiesbeck G. A., Bloch N., Aeschbach S., Olbrich H. M., Seifritz E. et al. Psychobiological responses to drug cues before and after methadone intake in heroindependent patients: a pilot study. Eur Neuropsychopharmacol 2008; 18: 390-3.

39. Brown S. A., Vik P. W., Patterson T. L., Grant I., Schuckit M. A. Stress, vulnerability and adult alcohol relapse. J Stud Alcohol 1995; 56: 538-45.

40. Vielva I., Iraurgi I. Cognitive and behavioural factors as predictors of abstinence following treatment for alcohol dependence. Addiction 2001; 96: 297-303.

41. Zanarini M. C., Frankenburg F. R., Hennen J., Reich D. B., Silk K. R. Prediction of the 10-year course of borderline personality disorder. Am J Psychiatry 2006; 163: 827-32.

42. Skodol A. E., Pagano M. E., Bender D. S., Shea M. T., Gunderson J. G., Yen S. et al. Stability of functional impairment in patients with schizotypal, borderline, avoidant, or obsessive-compulsive personality disorder over two years. Psychol Med 2005; 35: 443-51.

43. Gunderson J. G., Shea M. T., Skodol E. A., McGlashan T. H., Morey L. C., Stout R. I. et al. The Collaborative Longitudinal Personality Disorders Study I: development, aims, design, and sample characteristics. J Pers Disord 2000; 14: 300-15.

44. Morey L. C. A comparison of three personality assessment approaches. J Psychopathol Behav Assess 1986; 8: 25-30.

45. First M. B., Spitzer R. L., Gibbon M., William J. B. W. Structured Clinical Interview for DSM-IV Axis I Disorders/Patient Edition (SCID-I/P). New York: New York State Psychiatric Institute, Biometrics Research Department; 1996.

46. Zanarini M. C., Frankenburg F. R., Sickel A. E., Yong L. The Diagnostic Interview for DSM-IV Personality Disorders (DIPDIV). Belmont: McLean Hospital; 1996.

47. Zanarini M. C., Shea M. T. The Diagnostic Interview for DSM-IV Personality Disorders-Follow-along Version (DIPDIV-FA). Belmont: McLean Hospital; 1996.

48. Keller M. B., Lavori P. W., Friedman B., Nielsen E., Endicott J., McDonald-Scott P. et al. The longitudinal interval follow-up evaluation: a comprehensive method for assessing outcome in prospective longitudinal studies. Arch Gen Psychiatry 1987; 44: 540-8.

49. Warshaw M., Dyck I., Allsworth J., Stout R. L., Keller M. B. Maintaining reliability in a long-term psychiatric study: an ongoing interrater reliability monitoring program using the Longitudinal Interval Follow-up Evaluation. J Psychiatr Res 2001; 35: 297-305.

50. Kaplan E. L., Meier P. Nonparametric estimation from incomplete observations. J Am Stat Assoc 1958; 53: 45781. 
51. Goldstein R. B., Dawson D. A., Daha T. D., Ruan J., Compton W. M., Grant B. F. Antisocial behavioral syndroms and DSM-IV alcohol use disorders: results from the national epidemiologic survey on alcohol and related conditions. Alcohol Clin Exp Res 2007; 31: 814-28.

52. Goldstein R. B., Compton W. M., Pulay A. J., Ruan W. J., Pickering R. P., Stinson F. S. et al. Antisocial behavioral syndroms and DSM-IV drug use disorders in the United States: results from the national epidemiologic survey on alcohol and related conditions. Drug Alcohol Depend 2007; 90: 14558.

53. Morgenstern J., Labouvie E., McCrady B. S., Kahler C. W., Frey R. M. Affiliation with Alcoholics Anonymous after treatment: a study of its therapeutic effects and mechanisms of action. J Consult Clin Psychol 1997; 65: 768-77.

54. Bottlender M., Preuss U. W., Soyka M. Association of personality disorder with type A and type B alcoholics. Eur Arch Psychiatry Clin Neurosci 2006; 265: 55-61.

55. Grilo C. M., Becker D. F., Fehon D. F., Edell W. S., McGlashan T. H. Conduct disorder, substance use disorders, and co-existing conduct and substance use disorders in adolescent inpatients. Am J Psychiatry 1996; 153: 914-20.

56. Johnson J. G., Cohen P., Skodol A. E., Oldham J. M., Kasen S., Brook J. S. Personality disorders in adolescence and risk of major mental disorders and suicidality during adulthood. Arch Gen Psychiatry 1999; 56: 805-11.

57. Cohen P., Chen H., Crawford T. N., Brook J. S., Gordon K. Personality disorders in early adolescence and the development of later substance use disorders in the general population. Drug Alcohol Depend 2007; 88: S71-S84.

58. Franken I. H. A., Hendriks V. M. Early-onset of illicit substance use is associated with greater axis-II comorbidity, not with axis-I comorbidity. Drug Alcohol Depend 2000; 59: 305-8.

59. Verheul R., Kranzler H. R., Poling J., Tenne H., Ball S., Rounsaville B. J. Co-occurrence of Axis I and Axis II disorders in substance abusers. Acta Psychiatr Scand 2000; 101: 11018.

60. Gunderson J. G., Weinberg I., Daversa M. T., Kueppenbender K. D., Zanarini M. C., Shea M. T. et al. Descriptive and longitudinal observations on the relationship of borderline personality disorder and bipolar disorder. Am J Psychiatry 2006; 163: 1173-8.

61. Gunderson J. G., Stout R. L., Sanislow C. A., Shea M. T., McGlashan T. H., Zanarini M. C. et al. New episodes and new onsets of major depression in borderline and other personality disorders. J Affect Disord 2008; 111: 40-5.

62. Bornovalova M. A., Lejuez C. W., Daughters S. B., Rosenthal M. Z., Lynch T. R. Impulsivity as a common process across borderline personality and substance use disorders. Clin Psychol Rev 2005; 25: 790-812.

63. Dawson D. A., Grant B. F., Stinson F. S., Chou P. C., Huang B., Ruan W. J. Recovery from DSM-IV alcohol dependence: United States, 2001-2002. Addiction 2005; 100: 28192.

64. Verheul R. Co-morbidity of personality disorders in individuals with substance use disorders. Eur Psychiatry 2001; 16: 274-82.

65. Galen L. W., Brower K. J., Gillespie B. W., Zucker R. A. Sociopathy, gender, and treatment outcome among outpatient substance abusers. Drug Alcohol Depend 2000; 61: 23-33.

66. Gunderson J. G., Bender D., Sanislow C., Yen S., Bame Rettew J., Dolan-Sewell R. et al. Plausibility and possible determinants of sudden 'remissions' in borderline patients. Psychiatry 2003; 66: 111-19.

67. Ball S. A., Cobb-Richardson P., Connolly A. J., Bujosa C. T., O'Neall T. W. Substance abuse and personality disorders in homeless drop-in center clients: symptom severity and psychotherapy retention in a randomized clinical trail. Compr Psychiatry 2005; 46: 371-9.

68. Ball S. A. Comparing individual therapies for personality disordered opioid dependent patients. J Pers Disord 2007; 21: $305-21$

69. Linehan M. M., Dimeff L. A., Reynolds S. K., Comtois K. A., Welch S. S., Heagerty P. et al. Dialectical behavior therapy versus comprehensive validation therapy plus 12-step for the treatment of opioid dependent women meeting criteria for borderline personality disorder. Drug Alcohol Depend 2002; 67: 13-26.

70. Gregory R. J., Remen A. L. A manual-based psychodynamic therapy for treatment-resistant borderline personality disorder. Psychother Theor Res Pract Train 2008; 45: 15-27. 